\title{
Global learning \& progressive school change
}

\author{
Andrew Gitlin \\ University of Georgia, USA
}

\begin{abstract}
This paper describes a new platform developed to further progressive school change-UnEarth. One assumption of this site concerns the importance of sharing knowledge among communities of difference. By doing so, these communities push against normative boundaries by valuing diverse genres of knowledge. This acceptance of value across difference allows these communities of difference to connect in more democratic and collaborative ways then is usually the case. UnEarth also assumes that change requires a double move such that installations for change go hand in hand with a reconsideration and a reworking of what is the classroom or more generally the space for the change. Finally, UnEarth assumes that change requires, in part, an open text. An open text encourages change participants to go beyond any prior notion of what is desired and related actions associated with change. Within an open text format the change process is likely to occur in ways not known nor structured by the author or predetermined assumptions of the change process, thereby allowing long standing notions such as the classroom to be reconsidered conceptually and practically.
\end{abstract}

\section{Introduction}

The problem of school change has been with us forever [25]. From Dewey [9], to Sarason [25], Fullen and Hargreaves [11], Cookson and Schneider [6], Levine [18], DOE (2009) and Wrigley [26] the problems and potential solutions to school change have been well articulated. At best, as the Ford foundation [23] has found, these changes have altered schooling in minimal ways and even when significant change has occurred, it has been short lived. The result of this stasis is that historically and currently the best predictor of school change is still socio-economic status [24], [2]. Race is not far behind as a key factor in school success with African-American' and Latino cultures' having disproportionate high numbers in special education classes and disproportionate low numbers in Honors and Advanced Placement classes [21]. And this account ignores how African-American males and women in general get socialized in schools such that possible futures are constrained and thought to reside outside of their "normal" identity formation [10]. The record of school reform and change therefore raises enough questions to encourage educational actors of all stripes to search again, to research, the underlying assumptions and practical solutions associated with the change process and practice.

UnEarth [12] is a project I started 7 years ago that views difference as a benefit to be enhanced not a problem to be solved. My intention in developing UnEarth is to produce an internet site based primarily on four assumptions: In contrast to networking sites like

Facebook, Twitter, LinkedIn or e-learning courses, one central assumption for UnEarth concerns the importance of a) sharing knowledge among communities of difference (e.g., bringing together parents, students, teachers, and professors, professionals and clients/patients to connect their knowledge and act on education, schooling, and institutions of all kinds).

To encourage communities of difference to push against normative boundaries such as classrooms, departments, disciplines, clinics, law offices and corporations, etc., it is essential to embrace the view that diverse groups and cultures have something to contribute in terms of knowledge sharing. UnEarth does not begin a priori with the belief that a certain group knows more than others or knows better than others. [22].

Rather, the assumption is that groups bring differing orientations, possibilities, and limits to the knowledge sharing process. This acceptance of value across difference, not value as hierarchically distributed across groups and cultures, is a key to allowing these communities of 
difference to connect in more democratic and collaborative ways[4] than is usually the case. Additionally, most networking sites and e-learning classes saturate the field and space of the network by accepting many aspects of the classroom, office or change space as given. For example, e-learning works within constructed boundaries of the classroom to provide access to university teaching without leaving your home or convenient location. What e-learning classes don't even attempt to do is alter or rethink the nature of assignments, curriculum, pedagogy, etc. except to make it applicable for on-line learning. Instead, the central goal is increasing student numbers at reduced cost by having one professor instruct almost unlimited numbers of students. UnEarth, in contrast, encourages alterations in the concept of curriculum, assignments, pedagogy, because the formation of communities of difference allows for learning communities within the class and beyond the classroom making communication cross all sorts of differences. Learning as fostered on the UnEarth site is not limited to current classroom or office structures and predetermined spaces. Instead, UnEarth assumes that change requires a double move such that b) installations for change go hand in hand with a reconsideration and a reworking of what is the classroom or more generally the space for the change [19]. Further, UnEarth assumes that change requires, in part, an open text [15].

An open text encourages change participants to go beyond any prior notion of what is desired and related actions associated with change. Within an open text format the change process is likely to occur in ways not known nor structured by the author or predetermined assumptions of the change process, thereby allowing long standing notions such as the classroom or office to be reconsidered conceptually and practically.

E-learning and other networking sites do not leave these empty spaces and thereby direct participants to move explicitly in a particular direction. It is no accident, for example, that Facebook is primarily about images, given that image sharing is a central feature, focus and category of the network.

By leaving empty spaces, UnEarth moves the network beyond solely trying to achieve this or that to also giving members a significant mount of freedom (e.g., what communities are formed and therefore how knowledge is shared and used on the network). Because UnEarth stays with the student, client, patient, etc. and allows this individual to create a record of their learning experiences and accomplishments as well as changing learning desires, the teacher/professor "other" can get to know the "student" in ways not possible on other sites. This facilitates a more continuous process of learning that builds on what is missing within the learners' portfolio/resume and the strengths they bring to the learning table. With this comparative narrative on the unique nature of UnEarth in place it is time to discuss in more depth two of these key assumptions.

\section{Difference as a Benefit}

Sharing of some sort is surely not new nor of particular importance in itself. However, when sharing is part of a community building process and the communities attempt to span differences that typical keep groups and individuals apart, learning within the community has a chance to consistently rethink the habits and traditions that may be holding educational actors back from seeing and acting on unknown possibilities [8].

One such difference that keeps indivduals and groups apart is the difference between knowledge users and producers. Currently, the roles between knowledge users and knowledge producers are quite defined within the school context [13]. This is not to say that in practice all roles are precisely bounded in these ways. Rather, it is to say that certain roles are supported and conceptualized to be user or producer. It is expected, for example, that a professor produce new knowledge, attend conferences, and participate in any number of research activities.

A professor's salary is dependent, in part, on how well they achieve within this aspect of their job. In contrast, teachers are not expected to produce new knowledge nor attend research conferences and do related research activities. Surely, teachers participate in these activities in spite of these limits but it is not part of their job description nor are they usually given pay increases for doing so. This is why within the school context teachers, students, and parents are seen as knowledge users, while professors are seen as knowledge producers. It is true that Ph.D. students do a bit of each, but still the knowledge production part is under the supervision of professors, where this supervision does not occur for professors themselves. And teachers do action research [5] on a fairly regular basis but again this is in addition to their everyday roles and also often in collaboration with professors or academics of some ilk.

UnEarth enters into this construction as an interloper, as suggesting a new set of possibilities. In particular, the values underlying the knowledge 
sharing assumption found in UnEarth are two fold: that at times the sharing can be and should be between all combinations of professor, teacher, student, and parent and in other cases between professors who typically only share research activities within a discipline, department, program, or other structured community.

UnEarth is "wired" to facilitate these activities by providing equal access and opportunities for knowledge production, use and sharing regardless of role expectations and reinforcing structural boundaries.

UnEarth also makes this production, use and sharing of knowledge easy by allowing anyone to form communities of their choosing, to create spaces to store and organize knowledge in UnEarth libraries, and to allow all to make those histories open to others if they so desire. The production, use and sharing of knowledge, therefore, takes place in a context such that additional actors can be both users and producers of knowledge and share what they have learned with others. Furthermore, the establishment of communities of difference also tries to straddle divides between knowledge producers.

UnEarth softens these divides by forming virtual communities centered on collaborative attempts to problem solve.

This type of community lets educational actors to move outside their silos, even if only for a particular time period by a single keyboard stroke. These moves to challenge normative divides, and build communities of difference also go hand in hand with challenges to the boundaries of what counts as legitimate knowledge.

Where, for example, knowledge is typically seen as written, "space based", UnEarth has wired in the possibilities to include visual, "time based" and the written and oral as legitimate knowledge representations [17].

\section{Open Text}

The notion of an open text is one that is well known in literature circles [15] and within art theory generally [3]. It stands as a significant point of departure, however, when considered in relation to school change. One seemingly reasonable assumption in school change policy is the need for specific direction on what practitioners should do and how they should approach their relationships with students. In fact, it is often assumed that the most practical and effective forms of reform do exactly that - they fill out the directional field as completely as possible. The so-called teacher proof curriculum is but one exemplar [7]. While doing so is not necessarily a problem it does have its drawbacks. One significant drawback is made clear in Heiddeger's [19] writing on sculpture. In his account of the sculpture done in the time of Nazi Germany, Heiddeger talks about the Nazi's abhorrence for ambiguity and the need to define the human figure as an unusually detailed articulation of musculature such that it reflects the utter infusion of will and discipline [19] (82).

According to Heiddeger, this need for detail and the abhorrence for ambiguity resulted from their desire to control the ideal and boundaries of what it meant to be a good German, the German identity, at that time. The limitation of course, is that while control was enhanced, human growth and development was stunted.

In contrast to this overly defined idealized form, Heiddegger argues that unfinished and "open" aspects of a body found within sculptural forms allows for the body to grow into the unknown new spaces of the future as the spaces radiate into and change the body. A central issue of the influence of the sculpture on society and the issue of school change is the means through which change occurs - control and/or growth.

UnEarth takes the middle ground position by suggesting both. There is, however, a significant caveat. Control only works in the long run for school change proposals that can anticipate correctly changes in the context for schooling. And without this sort of futuristic wisdom, control is likely, by itself, to lead more to push back then long lasting innovation. Given the limitations of our wisdom, directional encouragement should be given some currency.

UnEarth, for example, provides directional encouragement in terms of the building of communities of difference and yet still leaves lots of open spaces for participants to make many alternative choices, thereby continuing the creative process of working with the unknown, allowing participants to adapt to future school contexts, and going beyond the wired aspects of UnEarth itself. There is almost no direct control (you must do this or that) built into UnEarth and if successful this network will change and evolve as schooling and its context do as well. This is what is intended by saying that UnEarth is an open text platform. But how does UnEarth interact with an evolving context including long standing features? It is this question that is addressed next?

\section{Long Standing Aspects of Schooling}

It is confusing in some regards that most school reforms do little or nothing in terms of 
rethinking or reforming long standing aspects of schooling such as the classroom, textbooks and go stop go education. UnEarth works on these long standing aspects of schooling while simultaneously trying to give directional encouragement in a number of different ways to the participants of the network.

\subsection{The Classroom}

The classroom is one of the most dramatic longstanding aspects of schooling. Globally, most school classrooms (all levels including university) today are self--contained. It is true that more than a few classrooms have flexible curtains but even in this case the classroom is still contained relative to the many possible configurations that might be desirable. UnEarth does more than make it possible to double the classroom size. Specifically through the formation of communities, the classroom can be divided into ever changing minicommunities, classrooms can also be linked together, and students within and across classrooms and schools can be connected within emergent learning communities.

\subsection{Textbooks}

Textbooks are another longstanding aspect of schooling (at all levels including the university). The problem with a textbook is that no matter how internally inclusive, this text can't anticipate in any sort of specificity the needs of a diverse array of students who are engaging with the textbook. However, by supplementing textbooks with UnEarth Libraries, depositories of individual or community knowledge production, use, and study, "textbooks" can be directly linked to student interests and ambitions and shared with others in the learning community. This expansion of the boundaries of the classroom makes more likely a closer relation of student interest, need and engagement with the curriculum while still covering the required material.

\subsection{Go Stop Go Education}

Schooling at all levels is discontinuous. For universities it is divided by semester, year of schooling completed, major or minor, and more primary levels of schooling are divided by age/ grade. There is nothing inherently wrong with this system except that in most if not all situations there is duplication and gaps in the learning process for the majority of students. This system, as is true of the classroom and textbook, is not going anyway anytime soon. However, it can be supplemented through the use of the UnEarth and in particular UnEarth libraries and Profiles. These central aspects of UnEarth are directed to account for learning needs, interests, texts studied, learning communities accomplishments, experiences readings etc.. Much more so than grades, and the informal conversations between teachers/professors about a student, this type of information allows each "new" teacher/professor to build on strengths and minimize weaknesses for each student. The education is more personalized and continuous as opposed to go stop and go and standardized.

\section{Conclusion}

UnEarth takes an initial stance toward furthering progressive change. It is true that UnEarth has some features typical to other sites. At the same time, UnEarth has some very significant differences not the least of which are the formation of within class communities, expanding beyond the class to include others in the "classroom" community, and connecting past, present, and future classes as linked learning communities [14]. Besides community building, UnEarth has the unique ability to create learning histories for individuals and communities. These histories keep a record of readings, tests, learning accomplishments, etc., which allows for knowledge sharing, continuity and building within and between classes as well as the ability to get to know students in a way currently not possible both before class starts as well as during the term for the class [16].

The possibilities of UnEarth suggests it is time for those interested in education to take a long look at our fears about youth and their learning proclivities [20] and join them while not abandoning more traditional forms of learning. If we do, technologies such as UnEarth can broaden and alter long standing aspects of schooling such that more students have the opportunity for success in schools as the notion of what it means to be educated is also made more inclusive.

\section{References}

[1] Beaumont, P. (February, 2011). The truth about twitter, Facebook, and the uprisings in the Arab World. The Guardian. Internet: February 24. 1-7. 
[2] Berliner, D. (2005). Our impoverished view of educational reform. Teachers College Record ,http://www.tcrecord.org/content.asp?contentid=12 106

[3] Bondanella, p. (2005). Umberto Eco. Cambridge: Cambridge University Press.

[4] Borman, K. \& Greenman,N. (1994). Changing American education: Recapturing the past or inventing the future. New York: SUNY Press.

[5] Carr, W. \& Kemmis, S. (1986). Becoming critical: Knowledge, power and action research. London: Routledge-Farmer.

[6] Cookson, P. \& Schneider, B. (1995). Transforming schools. New York: Garland Press.

[7] Darling-Hammond, L. (1993). Professional development schools: Schools for developing a profession. New York: Teachers College Press.

[8] Dewey, J. (1938). Experience and education. New York: Collier Books.

[9] Dewey, J. (1929). The quest for uncertainty. New York: Milton Balch Publishing.

[10] DOE (2009) Race to the top: Executive summary Washington D.C.: DOE publishing

[11] Fordham, S. (1996). Blacked out: Dilemmas of race, identity and success at Capital high. Chicago: University of Chicago Press.

[12] Fullan, M. and Hargraves, A. (1996). What's worth fighting for in your school. Second Edition. Toronto, Ontario: Public school teacher federation.

[13] Gitlin, A. ( 2014). UnEarth. Atlanta: GraySkyeMedia.

[14] Gitlin, A. (2009). Action research and social justice: Moving between subjective science and experimental art. Oxford Journal of Social Policy. 20 (4) $32-46$.

[15] Goodman, J. (1992). Elementary schooling for critical democracy. New York: SUNY Press

[16] Hejinian, L. (2000). The language of inquiry. Berkeley: University of California Press.
[17] Howard, G. (2006). We can't teach what we don't know: White teachers, multiracial schools. New York: Teachers College Press.

[18] Innis, H. (2007). Empire and communications. Lanham, Maryland: Rowman \& Littlefield Publishers.

[19] Levine, D. et. al. (1995) Rethinking schools: An agenda for change. New York: New York Press.

[20] Michell, A. (2010). Heidegger among the sculptors: Body, space, and the art of dwelling. Stanford: Stanford University Press.

[21] Oakeshott, M. (1995). Work and play. In First Things 1-6 Internet.

[22] Oaks, J. (2005). Keeping track. How schools structure inequality. New Haven: Yale University Press.

[23] Olson, M. \& Craig, C. (2005). Uncovering cover stories: Tensions and entailments in the development of teacher knowledge. Curriculum Inquiry 35:2. 161-182.

[24] Petrovich, J. (2008). Strategies for improving public education. New York: Ford Foundation.

[25] Protor, B.D. \& Dalaker, J. (2002) Poverty in the United States: 2001.Washington DC: U.S. Government Printing Office 60-219.

[26] Sarason, S. (1990). The predictable failure of educational reform. San Francisco: Jossey-Bass.

[27] Wrigley, T. (2011). Paradigms of school change. Management of Education 25, (2) 62-66. 